\title{
Introduction: The prospects for mobile learning
}

\author{
John Traxler $\cdot$ Steve Vosloo
}

Published online: 17 April 2014

(C) UNESCO IBE 2014

\begin{abstract}
The issue that this article introduces grew out of an event, the UNESCO Mobile Learning Week, but also out of a wider and growing movement of people and organisations exploiting mobile technologies, as they pursue varied educational missions. The UNESCO Mobile Learning Week represented by contributions here was a focus for contributions from across the field. This article provides a wider discussion of these contributions, first by looking at the achievements of UNESCO and then by considering these achievements more critically. In particular, it highlights several sets of inherent challenges facing UNESCO and other organisations engaging in mobile learning: those around evidence, evaluation, and sustainability; the problematic tension between largescale interventions, based on scale and content delivered by national governments, and the language and culture of marginal or indigenous people; the absence of appropriate ethics procedures to manage educational interventions delivered by a powerful and ubiquitous technology; and the absence of learners in the forums that address all these various issues.
\end{abstract}

Keywords Mobile learning - Literacy · Teacher development - Sustainability · Curriculum · Education for All · UNESCO - Access to education · Education quality

The field of information and communication technology (ICT) for education has been active for the last two decades, based largely on personal computer laboratories in schools,

Steve Vosloo has since left UNESCO. The UNESCO contact person for issues related to mobile learning is Francesc Pedró, f.pedro@unesco.org.

J. Traxler $(\bowtie)$

University of Wolverhampton, Wulfruna Street, Wolverhampton WV1 1SB, UK

e-mail: john.traxler@wlv.ac.uk

S. Vosloo

UNESCO, 7 Place Fontenoy, 75352 Paris 07 SP, France

e-mail: stevevosloo@gmail.com 
telecentres, and, where people are fortunate enough, in homes. Within this field, the recent spike in global access to mobile devices, in particular mobile phones, presents a significant opportunity. Access to ICT has long been a challenge for most learners and educational institutions, hence the need to set up school- or community-based facilities. Even in a relatively well-resourced developing country like South Africa, it is not uncommon for a school of 1,000 learners to have only one computer room with 30 PCs.

The mobile device revolution stands in stark contrast. At the end of 2012, there were around 6.8 billion mobile phone subscriptions in the world (ITU 2013), held by an estimated 3.2 billion subscribers - many people have more than one SIM card (GSMA 2012). What is particularly staggering about these figures is that they represent growth in the developing, as well as developed regions. While the fixed-broadband Internet penetration rate is under $1 \%$ in sub-Saharan Africa, mobile-broadband penetration is $11 \%$, and growing the fastest of any region in the world, up from 2\% in 2010 (ITU 2013).

Sales of tablet computers have also skyrocketed. Governments have led large implementations of tablets at all levels of education - primary, secondary, and tertiary - and in a range of countries, including the United States, Thailand, Turkey, Uruguay, and Mauritius.

Of course, access to ICT is only one piece, albeit a necessary one, in the puzzle of how to effectively utilise technology to support and improve education. Issues of pedagogy, content, training and support, and assessment, to name but a few, are essential for ensuring educational impact. For several years, those involved in mobile learning have been piloting and researching projects based on a broader view than just the technology itself; they can now point to significant achievements and insights. Mobile learning helps reach marginalised populations and improve education systems; it provides opportunities to expand educational access in ways not possible before; and it supports instruction, administration, and professional development. Learners and teachers from Mozambique to Mongolia are using mobile devices to access educational content, converse and share information with other learners, elicit support from peers and instructors, and facilitate productive communication (West and Vosloo 2013).

While the field of mobile learning is not new, in recent years it has received vastly increased attention from seasoned mobile learning researchers and practitioners, as well as new entrants into this space. This surge in interest is likely a combination of the huge increase in access to mobile technology, mounting evidence around the educational efficacy of mobile learning and, for industry, the potential for commercial gains. Many of the relative newcomers, like UNESCO, have traditionally been involved in ICT in education more generally and are now turning their attention to the promise of mobile learning to complement their existing efforts.

\section{Education for All and the role of UNESCO}

In 2000, the Education for All (EFA) movement, which was first launched in 1990, was further affirmed when participating countries and international organisations identified six key education goals that aim to meet the learning needs of all children, youth, and adults by 2015. UNESCO was mandated to coordinate the international efforts to reach Education for All and to measure progress towards reaching the goals.

As the lead UN agency for education, UNESCO seeks primarily to serve the most vulnerable and disadvantaged, including the least-developed countries, women, and youth. All of its education efforts, from early childhood care and education (ECCE) to mobile learning, seek to support the achievement of quality education for all. 
One of its five core functions is to be a clearinghouse for "gathering, transferring, disseminating and sharing available information, knowledge and best practices in its fields of competence, identifying innovative solutions and testing them through pilot projects" (UNESCO 2009, para. 3). Organising and participating in meetings or exchange networks for the sharing of research, projects, and ideas is a key activity of the clearinghouse.

While UNESCO has a broad mandate that covers many different areas, it operates within a context of limited resources, be they human, financial, or material. It thus has to focus its efforts, where possible, in order to seek the greatest impact in key areas. Two such areas of focus are the support and professional development of teachers as a way to increase education quality, and a focus on achieving gender equality in education. Priority Africa is also a core strategy as the organisation works to strengthen education efforts on the continent.

While UNESCO has been exploring mobile learning since 2005 (UNESCO 2005), its coordinated and deliberate focus on mobile learning began in 2010, after it signed on to a partnership agreement with Nokia, pledging to "promote the use of mobile technologies to further the objectives of Education For All" (UNESCO 2010, para. 1).

Against the backdrop of UNESCO's mandate, functions, and focus areas, it is obvious that its work in mobile learning should support the achievement of EFA, as well as teacher development and gender equality. In the next section, we describe UNESCO's key activities in mobile learning, largely in partnership with Nokia and the U.S. Department of State, and how they relate to its overall strategy. We then point out a series of challenges to mobile learning, and conclude with some work in progress.

\section{UNESCO's key activities in mobile learning}

Mobile technology and teacher development

To improve education quality, at least in formal education, it is necessary to improve the quality of teachers. The world currently faces a grave challenge: not enough qualified and motivated teachers are available to achieve the EFA goals. The UIS (2013) estimates that to achieve universal primary education by 2015 , countries would need an extra 1.6 million teachers in classrooms. Beyond the EFA target date of 2015, this number will rise to 3.3 million teachers needed by 2030 . Geographically, the shortage and under-qualification of teachers is most acute in sub-Saharan Africa. Given this challenge, it is crucial to explore every serious opportunity to support teachers and improve their professional development-and mobile learning is one such opportunity.

In 2012, UNESCO published six papers that examine how mobile technologies can support teachers and improve their practice: Dykes and Knight (2012); Fritschi and Wolf (2012a); Isaacs (2012a); Jara, Claro, and Martinic (2012); and West (2012). The papers highlight illustrative initiatives from five major regions: Africa and the Middle East, Asia, Europe, Latin America, and North America. The sixth paper, with the title Global Themes (West 2012), synthesises central findings from the five regional papers. The papers are by no means exhaustive in their coverage of initiatives, but they do shine a spotlight on key projects and identify crosscutting themes, trends, and challenges. The finding below from the Africa and Middle East paper is indicative of the wider trend in this space:

$[\mathrm{N}]$ early all teachers, including those who are privileged with access to a personal computer (PC) or laptop, will invariably have access to a mobile phone, a situation 
which holds great potential for using mobile phones in teacher development. However, research based evidence that mobile phones can enhance and support teachers' professional development and [open and distance learning] in the region is very sparse. The projects that do exist have been mostly experimental and conducted in isolation from existing teacher development programmes. (Isaacs 2012a, p. 6)

The papers revealed the enormous potential for mobile learning to support teacher development—but more projects and research are needed to realise this potential. To this end, UNESCO is currently implementing four mobile learning pilot projects for teacher development in Nigeria, Senegal, Pakistan, and Mexico. Each project is focused on developing the capacity of early childhood or primary school teachers and improving their classroom practice. The subject areas include ECCE, mathematics, Spanish, and English. Each project involves a local teacher-training institute to ensure local buy-in and educational relevance.

Mobile learning does not seem to be routinely established in the school curriculum, either as a delivery mechanism or as a subject at a national or institutional level. Only through teacher development, either initial or in-service, is this likely to change. Botha et al. (2012) report on a mobile learning curriculum framework that has been devised and is now being tested. For teacher development agencies, such as teacher training colleges, it would provide trainee teachers with a formal curriculum, including the kind of formal documentation—curriculum, assessments, delivery methods, etc.- they need. The content of such programs is straightforward and ranges from technology through education to sociology with an obvious focus on the intersection of the three, but assessment, quality, and delivery are more problematic and go to the heart of different conceptions of learning in different cultures at different levels.

Mobile learning, literacy development, and gender equality

UNESCO has launched a project to better understand how to empower women and girls through education via innovative mobile technology-based learning and information programmes. A particular interest is helping newly literate women and girls to retain and improve their literacy skills. UNESCO has conducted a comparative analysis of effective initiatives for developing literacy through mobile phones to empower women and girls; it aimed to identify practices that ensure that programmes are sustainable and to offer opportunities to scale up particularly promising approaches. These findings are being consolidated in a report consisting of two regional reviews-on Africa and on Asia and the Pacific - as well as eight case studies of specific examples.

\section{Mobile learning and policy}

As part of UNESCO's role as a clearinghouse, it offers guidelines to its member states on a range of issues. It has sought to do this for mobile learning. As with the teachers' initiatives, it began by commissioning a series of papers that considered mobile learning initiatives from around the world, this time with a lens on their policy implications. Overall, the authors of the five regional papers (Fritschi and Wolf 2012b; Hylén 2012; Isaacs 2012b; Lugo and Schurmann 2012; So 2012) found few policies for mobile learning that they judged to be considered and thorough.

However, because mobile learning is a relatively recent phenomenon, many of these policies were developed in the pre-mobile era. The few policies that do refer to mobile devices do so tangentially; in some cases they ban them. In addition to the initial papers, 
UNESCO has set out to offer guidance to its member states in three publications. The Future of Mobile Learning: Implications for Policy Makers and Planners (Shuler, Winters, and West 2012) discusses the likely impact that mobile technologies will have on education in the future and the important policy decisions required today. The other two publications are Mobile Learning and Policies: Key Issues to Consider (Vosloo 2012), and the UNESCO Policy Guidelines for Mobile Learning (West and Vosloo 2013).

The guidelines were developed collaboratively over the course of 2012: input was sought from specialists in fields as diverse as education, communication, and technology; and contributions were received from over 20 UNESCO member states as well as members of the public. Three main goals underpin the guidelines: to raise awareness of mobile learning and put it onto the agenda for ICT in education, to describe the unique benefits of mobile learning, and to outline key issues to consider and recommend elements of policies that will enable mobile learning.

Because the guidelines speak to all member states, from Singapore to South Sudan, they are necessarily broad in nature; these two countries represent vastly different education contexts and stages of ICT in education maturity. For the guidelines to be of value, they need to be adapted to the local context of each country. The hope is that governments around the world will engage in this process of localisation, now that the guidelines have been published. The interpretations and adaptations of this process should be recorded, to inform future versions of the guidelines.

\section{Mobiles for Reading}

The Mobiles for Reading project studies how people use mobile technologies for reading. It hopes to provide governments and other relevant stakeholders with information that will help them better leverage and tailor mobile technologies to advance literacy, especially in developing countries that are often "book-poor" but "mobile-phone" rich. To complete this project, perhaps the first of its kind, UNESCO has partnered with Worldreader, a nonprofit organisation that optimises books for consumption on mobile and other digital devices. Over 4,000 users of the Worldreader mobile app were surveyed in seven countries: Nigeria, Kenya, Ghana, Zimbabwe, Ethiopia, India, and Pakistan. The final report, which will provide insights into the benefits and challenges of mobiles for reading, will be released at the UNESCO Mobile Learning Week in February 2014.

\section{Mobile Learning Week}

As part of its role as a clearinghouse of ideas, UNESCO has hosted two international Mobile Learning Weeks (MLW), in 2011 and 2013, to better understand both the possibilities and the challenges of mobile learning. Over 300 people, from over 45 countries, attended MLW 2013: practitioners and researchers, and stakeholders in government, civil society, and industry. A forum for senior policymakers in education was convened during the week to allow government decision makers to share their experiences, strategies, and challenges around mobile learning implemented at large scale.

\section{Challenges for mobile learning}

Given the many educational challenges facing countries around the world, and the effects of the global recession that have further strained the already limited educational and human 
resources available, it is crucial to explore every possible avenue to support education, including mobile learning. However, these same factors also make it essential to critically examine mobile learning-in its many evolving forms and the ways it is practiced by the many new players - against its ability to deliver, enhance, and support EFA. The practice, discussion, and research — in the development, commercial, and academic spheres-must remain open, critical, and self-reflective. Only if that happens can all parties fully explore and leverage the opportunities that mobile learning offers, even as the priorities and values surrounding it are challenged.

Given this activity, it is timely to take the opportunity to stand back and reflect on it in a wider historical and political context. In many respects, current work at UNESCO resonates with themes across a broader front of agencies, foundations, ministries, and NGOs, all of them keen to exploit mobiles to deliver their educational and humanitarian missions to developing regions - and that eagerness adds some broader relevance to this reflection. The resonance we observe may not be surprising, given the considerable overlap and intermingling of people and events, drivers, values, and perceptions on many of the issues.

But this argument is difficult to develop and sustain systematically, since the contributions presented here are but a sample of those at the Mobile Learning Week, themselves only a skewed sample of activity and dissemination in the wider field. Ken Banks, in an invited piece for this special issue, looks at mobile learning from an experienced and upbeat mobiles-for-development perspective; he sees infrastructure, handsets, and other aspects of technology as the principal obstacles to more widely accessible education, but obstacles that are being addressed.

The contributions from within Mobile Learning Week itself generally take more troubled and complex positions. Ally and his colleagues are most in sympathy with Banks' position and mood but question the relevance of the current evidence base, derived mostly from shortterm projects, in telling us about indicators such as retention and performance. Buckner and Kim, in their case study, focus on a specific mobile technology and its ability to transform pedagogy but report on a series of classroom interventions in different countries. Their account is also fairly upbeat but implicitly raises interesting questions about the relationships between pedagogy and culture. They all, along with Banks, see infrastructural and technological barriers falling and mention the need for changes in teacher development in order to exploit increased access to learning opportunities with mobiles.

Royle and his colleagues also address teacher development but it lies at the core of their contribution, which attempts to reconcile a radical and mobile view of societies with the institutions and expectations of teacher development. In their contribution, which also draws on the cultural, social, and pedagogical aspects of learning with mobiles, Ranieri and Pachler explore the potential of mobile learning in adult education with a particular focus on identity formation and self-representation, testing the use of mobile devices as cultural and learning resources for identity (trans)formation by and social empowerment of adults. Wagner and his colleagues, in reviewing the nature of evidence from a robust sample of projects in the mobiles for literacy domain, question the nature of success; this question resonates with Ally's concerns about the predictors of success. Their response is to reconceptualise success by developing techniques for monitoring and evaluation. Where Wagner and his colleagues tackle mobiles' capacity to deliver literacy, Semali and Asino tackle mobiles' capacity to transform literacy. They explore the impact of mobiles on literacy and postliteracy, finding that phones and applications offer vital resources for postliteracy practices, maintaining and enhancing previously acquired literacy skills. All these articles repay critical and repeated reading in order to expose the points of similarity and the points of difference. 
Scale and sustainability

The most obvious and persistent of these issues, marking the current era as different from the preceding decade, are those of scale and sustainability. This is hardly a surprise, given the decreasing proportion of mobile learning researchers and educationalists involved in this current incarnation of mobile learning and the increasing proportion of agencies, consultants, policy-makers, and corporations involved. If mobiles are a possible delivery mechanism for education in the global South and amongst the disadvantaged, then scale and sustainability and various aspects of cost-effectiveness will inevitably, and understandably, loom large.

Sustainability and scale, however, are not new problems. They may have been built into mobile learning from its inception by the way it was often conceptualised: as an innovation within the research communities embedded within formal education. The mobile learning community has demonstrated several things in its first decade. The first is that mobile technologies can enrich, enhance, and challenge existing ideas of education, usually in ways that take it outside and away from the classroom, the lecture, the teacher, and the curriculum, specifically in developing the ideas of informal, contingent, collaborative, contingent, situated, contextual, and personalised learning (Traxler 2011). In disseminating and publicising these achievements, however, the mobile learning community has often failed to understand how it needs to position itself for various external audiences. If we look at some of the high-tech fixed-term projects with a large technology development component, these are clearly not sustainable or cost-effective in the immediate future. But they may, for example, be demonstrating what might be possible once bandwidth and hardware trickle down to the global South. Are they demonstrating a concept that can be repurposed onto simpler platforms in the global South? Do they say anything about scalability? Or do they, on the other hand, embody pedagogical assumptions that will not travel comfortably into other cultures? Sadly, researchers and developers have often focussed on the innovation, the tangible and the artefact, at the expense of the recipients or the hosts of their work-too often overlooking sustainability at a cultural level. These concerns have a bearing on the complex problem of sustainability.

The mobile learning community has also demonstrated that mobile technologies can take learning, or learning support, to peoples, communities, and regions for whom earlier established educational interventions would have been too difficult, expensive, or dangerous (Traxler 2012). Sometimes this is educational content, sometimes it is educational discussion, and sometimes it is advisory, administrative, or logistic support. This category includes using mobile technologies to overcome two kinds of barriers: those of distance, geography, environment, and infrastructure, along with those of personal, physiological, economic, social, or cultural distance or difference from the educational mainstream. These achievements are obviously nearer to a Millennium Development Goals agenda than the first set of achievements but often they can strengthen the central, the formal, the conventional, the organised, and the mainstream at the expense of the marginal, the unconventional, the unorganised, the informal, and the peripheral. It is easier to achieve scale and sustainability for these interventions, because they can be funded and delivered as addressing shortcomings and deficits, but they are more problematic, because of the inherent tendency to overlook the culture and preferences of learners.

Also, different governments have different ideologies about the relationships between central and national government and local, regional, and provincial government, even in monolingual countries. Consequently, it may not be possible-or desirable-to move them to scale. These differing ideologies depend on the government's size. Only big 
governments, which see the state's responsibilities to its people extending from the cradle to the grave, see the obligation to turn evidence into policy. These governments also need capacity. Evidence is useless without appropriate ideology and capacity. The evidence to support sustainability is likely to come from fixed-term subsidised projects, which, by definition, can provide little evidence about long-term sustainability. Also, they usually are small-scale projects—so they teach us little about large-scale possibilities. Governments typically operate at scale but few have the capacity, mechanisms, and ideology to fund activity that is explicitly intended to produce the evidence that justifies scale (Traxler 2010).

\section{Evidence and impact}

We can assume that sustainability will be based on profit or policy. A for-profit organisation must have a business case for sustaining mobile learning, while a not-for-profit one must have a reason to change its resource allocation, and a government must have a policy for sustaining it. Any given ecosystem of mobile learning may be a mixture of both, but governments and businesses will only shift their priorities and resources on the basis of evidence: the specific kinds of evidence that fit their individual value systems expressed in ways they can assimilate. These shifts involve risks and thus risk enters the equation alongside evidence, and the evaluation of both requires expertise. We can look back on ten or more years of mobile learning research and development around the world but see little or no sustainability because these issues have not been given sufficient priority. Instead, we find questions that are difficult to answer and therefore often avoided. Among them: what can the past tell us about the future? What can the small tell us about the big, and what can one place tell us about somewhere else? In short, how can the lessons of one (socio-spatiotemporal) context tell us something trustworthy and useful for another context?

In a research context, the evaluation of mobile learning projects has been both theoretically challenging and methodologically flawed. Such evaluation is difficult, for at least three overlapping reasons: the evaluation of meaningful education, the ethos of mobility evaluation, and the technology of mobile learning evaluation. When mobile learning occurs in development contexts, we can add a fourth problem: the lack of evaluation capacity in much of the global South. Here we unpack some of these problems.

First, how do we evaluate mobile learning in meaningful contexts? We can often only capture the education that happens inside schools - capturing what happens outside of schools or after school is much harder. In the context of formal education with its schools, its curricula, its timetables, and its buildings, researchers can straightforwardly define the hoped-for outcomes and can measure their presence, or otherwise, sometimes against baselines or control groups. Then, through sensible research design, they can separate the signal from the noise, eliminate the confounding variables, and identify correlation and cause. But the extent of our capture is not always meaningful-regardless of how tangible, objective, and quantifiable it seems - and the real change or outcome may take several decades to arrive. Many educators have aspirations to make education life-long and lifewide. Measuring these kinds of outcomes is much more worthwhile but also much more challenging, as are social, communal, or collective outcomes, as opposed to personal or individual ones. Furthermore, mobile learning is quintessentially interwoven with everyday life. These factors constitute the first challenge.

Where education is seen as a life-long activity with life-long consequences, evaluation is an attempt to evaluate phenomena whose most significant causes and effects may well be obscure, where multiple causes interact, and the timescales run into decades. Many years 
ago, the UK Department for Education issued a booklet about evaluation, with the title of Soft Outcomes and Distance Travelled. This captures the essence of the real challenge: measuring meaningful improvement.

A further challenge is evaluation in different/distant communities. These may be communities in cyberspace and "phonespace"; they may be communities of educationally disengaged and disenfranchised people in rustbelt Western Europe, or geographically distant communities in rural Africa. It is challenging because the farther the focus moves from a northern, western, metropolitan, institutional, and professional environment- the source of so much of the related discourse and perspective-the less chance there is that a shared language, shared confidence, and shared trust will inform any conversation about educational progress and educational outcomes, or even the nature of education itself.

Learning with mobiles, like most other activities with mobiles, is difficult to measure and monitor in any case. Until recently, it was technically too challenging, cumbersome, and contrived to capture interactions and activities on the fly, in the moment, and researchers resorted to the paradox of making learners stationary so that they could report on their mobile learning. Improvements in technology now let researchers monitor and measure learners on the move-and do so unobtrusively and accurately—so this is less of a challenge. But it is still not like evaluating formal education or learning with computers; issues of comparability and calibration remain. With both computers and formal education, the learners obviously stay still, remain in one place, and focus on the substantial task at hand. But even at its best, at its most quintessential, learning with mobiles is always lightweight, spontaneous, opportunistic, informal, and woven into everyday life. Again, separating the various causes and effects is a challenge, especially for researchers with a particularly empirical or experimental way of looking at life (Beddall-Hall and Raper 2010).

Furthermore, when researchers evaluate most aspects of mobile learning, they face many quite profound problems, ranging from the philosophical to the professional to the practical (Traxler and Kukulska-Hulme 2006). These reservations may be true but irrelevant; we may feel that mobile learning is no longer an innovation within institutional learning but a reflection of the world in which institutional learning takes place.

There is an argument that corporations, institutions, and ministries should ignore evaluation, evidence, and their metrics, and should instead support learning with mobiles because such learning is more closely aligned to societies permeated and transformed by mobiles. This idea may be less attractive to those corporations and ministries and their institutions that are not themselves permeated and transformed by mobiles. Recent political events have shown us ministries, officials, institutions, and practices swept away, rendered conspicuously static and irrelevant by mobiles in the hands of the masses.

We are not saying that evaluating mobile learning has now become pointless. Rather, we hold, evaluation is now needed to decide which mobile learning, not if mobile learning.

Content, language, literacy, and culture

Another major theme at the Mobile Learning Week, universally and uncritically shared across the community, was literacy, an apparently undifferentiated and unambiguously benign objective, one that mobiles can more easily deliver. UNESCO is committed to promoting cultural diversity but this is a complex and problematic issue in practice.

At one extreme, literacy is the consumption of content developed externally and delivered on e-book readers. These readers are a cheap and robust mobile technology that can easily take content into remote regions and at small provision scales. One example 
(Worldreader 2011) comes from Ntimigom Primary and Nursery Schools in Kilgoris, a town in Rift Valley Province, Kenya, where the mother tongue might be that of the Maasai, with their traditional semi-nomadic lifestyle, or perhaps that of the Gusii-speaking Kisii. The readers, however, deliver English and Swahili. Swahili is a lingua franca that has evolved along the entire coast and hinterlands of East Africa, whilst English has much higher status and is educationally desirable; either of them can undermine local mother tongues.

Furthermore, state education systems and their technologies have been used to "sedentarise" nomadic communities such as the Maasai, the San, and the Roma. They have also been used to emphasise the cultural hegemony of a country's dominant ethnic communities, of specific socio-economic classes, of educational elites, and of representatives of global power languages. In the current context, the technologies of the education system now include mobile technologies: technologies that are ubiquitous, pervasive, robust, familiar, and cheap, characteristics very different from the education system's other earlier technologies, such as computers and television. The education system's ability to deliver and support language and literacy through mobiles can now dramatically perturb the established dynamics between majority languages, mother tongues, and informal languages, and between mainstream and accepted cultures and fragile, peripheral, and marginal cultures. This is not of course to say that the earlier established dynamics were necessarily benign and that generally the balance of content on mobiles can only reflect the balance of previously published content. UNESCO's Policy Guidelines for Mobile Learning (West and Vosloo 2013) point this out, calling for local content in local languages:

Even when content is available [via mobile devices], it often lacks relevance to local student populations due to limited language options or a dearth of culturally-specific material. Additionally, a great deal of content fails to follow standards or incorporate features that improve accessibility for students with disabilities. Guideline: Promote the creation of mobile content that is relevant to local groups and accessible in local languages. (p. 33)

At the other extreme, some in the field believe that learning grows out of shared knowledge construction based in discussion amongst learners, but these too play out differently and differentially in different language ecosystems. These ideas require a different technological emphasis compared to learning based on content, and either approach may or may not match the expectations that a particular culture or community holds about the nature of learning.

A recent work from the British Council (Coleman 2011) analyses the political and ethical issues associated with the role of English as a global power language. It is often the default for distributed content on mobiles: sometimes ex-colonial English but increasingly often American English. Coleman does not address mobiles explicitly, though themes of social and geographical mobility feature frequently. But mobiles will obviously be a significant perturbation to the dynamics around language and they are themselves involved in the rapid evolution of language, dialect, idiom, and discourse. For example, Tembe and Norton (2011) explored the dynamics between mother tongues, the lingua franca, and power languages, and their respective relationships to the state education system in adjacent East African countries. They reported a preference for English, with ambivalence about KiSwahili and mother tongues, but this may vary elsewhere.

Several contributions to UNESCO Mobile Learning Week also drew attention to the complex issues of mobiles, language, and culture. For example, Dodson et al. (2013) 
reported on fieldwork with the womenfolk of Berber communities. These are tribal, traditional, Muslim, conservative, rural, arid, and poor communities. Women lack formal education and their livelihoods are tied to the argan tree for oil production and home consumption. They inhabit a complex language environment that includes multiple dialects and languages. Their two spoken dialects are Darija, an amalgamation of Arabic, French, and Spanish words, and Tachelhit, one of numerous Berber dialects. The two official written and spoken languages are French and modern Standard Arabic. They also encounter three alphabets: Arabic, Latin, and Tifinagh script (glyph-based but not widely used). Their mobile technology is simple - and usually broken, second-hand, or counterfeit. Though few people have smart phones, relatively good network coverage and power are available. Because of their complex literacy and language environment, women use their mobiles in very basic ways and cannot benefit from many phone features. Their attitudes, costs, and opportunities around language are shaped increasingly by mobile phones and like many people with inadequate literacy they devise sophisticated coping strategies. As Dodson et al. put it, "the inability to SMS may constitute a technology tax on illiterate women" (p. 1). One goal of their study was to explore the challenges of moving from oral communication (speaking and calling) to texting in a non-text based community, avoiding a formal educational approach because of shame and fear, and to expand the use of available mobile phones for personal and instrumental communication.

Some languages are only now emerging in written forms, a phenomenon that both telescopes and compresses the negotiation between oral, written, and mobile forms of expression, and with other parts of the language ecology. Rosenberg (2011) explores the impact of mobile technology on one of these, the N'Ko language, the standardised writing system for the Mande language family across eight West African countries:

Heritage languages like N'Ko are taking on new life thanks to technology. An Internet discussion group, Indigenous Languages and Technology, is full of announcements for new software to build sound dictionaries and a project to collect tweets in Tok Pisin, a creole language spoken throughout Papua New Guinea, or Pipil, an indigenous language of El Salvador. ... For many tiny, endangered languages, digital technology has become a lifeline. (para. 8)

Based on research at Swarthmore College, Rosenberg observes,

For the vast majority of the world, the cellphone, not the Internet, is the coolest available technology. And they are using those phones to text rather than to talk. Though most of the world's languages have no written form, people are beginning to transliterate their mother tongues into the alphabet of a national language. Now they can text in the language they grew up speaking. (para. 11)

The fragile Tuvan community now has an iStore app: a talking dictionary devoted to preserving its language and passing it on. It was created by the Living Tongues Institute for Endangered Languages and BoCoSoft Inc. Tuva is a region in southern Siberia and the Tuvan people have a rich tradition of orally transmitted folklore; its many genres range from very brief riddles and aphorisms, to tongue twisters, magical tales, hero tales, scary stories, and epics that take many hours to recite. The app is seen as helping preserve the language and hence the culture and identity of the Tuvan people (Colls 2009).

Rindel (2013) offers other insights into the complex and rapidly changing ecology of indigenous languages and mobile devices. She says linguists estimate about 200 indigenous languages are spoken in North America, with another 100 already extinct. In the early 1990 s, only about $11 \%$ were thought to still be passed traditionally from parents to children. As with our examples from Africa and Asia, the bulk of the surviving languages were 
spoken only by tribal members who were middle-aged or older. Most of these tribal languages are making a comeback, however, thanks to everything from apprenticeship programs that pair a fluent elder with a student, to immersion school programs. Many incorporate technology such as Facebook, YouTube videos of native speakers, and Google Hangout video chats for live, long-distance conversations; they refer to iTunes, iPads, and iPhones.

On a lighter note, in a spoof on 1 April, 2013, a major South African online newspaper reported that Mxlish had been included as South Africa's twelfth official language (News24 2013). Mxlish is the language of the MXit platform, densely populated with teenagers and young people and used for 40 to 50 educational or social projects at any given time. But the spoof made a serious point. South Africa has eleven official languages and several unofficial ones, including Tsotsitaal and Iscamtho. The latter have little support within the education system and may have subversive or counter-cultural connotations. Similarly, early Txt-speak had subversive and generational connotations, as Goggin (2006), Shortis (2007), and Thurlow (2003) all describe, but it was often quickly appropriated by the education system. These remarks only serve to emphasise the complex ecology of languages, mobiles, and education.

Finally, education is always a process of acculturation and transformation, a process of becoming a different kind of person, of coming to access different cultures and different discourses, of learning to speak the languages of the more learned. Thus, it is a political process. Mobiles accelerate, fragment, and complicate this dynamic. Here, two important questions arise. First, is this process one of reprogramming, of replacing and over-writing native, indigenous, or local languages and culture, or is it one of adding languages alongside them? Second, was this process knowingly and consensually invoked? Education raises complex ethical issues.

The ethics of learning with mobiles

We see a general assumption that we are all nice people doing good things with the best of intentions and that it would be ungrateful and ungracious - and inefficient - to slow things down by asking if we might cause harm. And it would be really, really inefficient to further ask who decides what constitutes harm. And it would probably be unthinkable to ask whose interests are being served (Traxler 2012).

Too often our Western ethical heritage drives us to explore the nature of our duty to educate others but not to explore the nature of our right to do so. We run the risk of a kind of ethical and cultural colonialism if we do not recognise ethical differences across cultures and a kind of educational determinism, analogous to technological determinism, that because we can teach then we must teach. Historically, delivering education to distant and different communities was difficult and the emphasis of ethics was on our duties to educate others. Now that technologies, especially mobile ones, make delivery much easier, perhaps the emphasis should shift to asking about our rights to educate others.

Informed consent is held to be the ethical gold standard in research involving people but the form this usually takes may rest upon the largely Western emphasis given to the individual at the expense of the community, and the largely Western emphasis given to that individual's written signature, expressing once and for all their assent to participate. With the complex, fluid, and abstract nature of the interactions and information afforded by mobile phones, and their possible wider impact on the community, this practice may no longer be as appropriate as it seems. 
This may, however, be a secondary issue. The primary issue is that the agencies, donors, foundations, corporations, and governments do not generally seem to have even an inadequate and immature procedure that would provoke these simple questions.

Within discussions on ethics, the learners seem to be continually omitted. In their absence, mobile learning might just be something that people like us do to people like them: distant, different, other, and unheard. This omission is easy to regret but almost impossible to address. Over the last four or five years, the university sector in the UK has tried to access insights into its learners' opinions on, and experiences of, e-learning in ways that are ethically defensible and methodologically sound, in ways that avoid the obvious pitfalls of being patronising, trivial, obvious, or skewed-but with only partial success. There are many accounts of this activity, for example the LEX (learner experience) programme funded by JISC (Creanor, Gowan, Howells, and Trinder 2006; Creanor, Trinder, Gowan, and Howells 2006). These are working across relatively small divides of distance, culture, and power, compared to those involved in sophisticated and well-resourced organisations in the North that are accessing the authentic learner voice of individuals and communities in the South. Organisers of the annual WISE conference in Qatar make similar attempts but given the nature of the event, these have been more problematic.

To return to our previous point, part of the difficulty in accessing the mobile learner voice is of course that the research ethics involved in exploring informal on-line behaviour are inappropriate and immature. These difficulties are compounded when we try to reach across the physical as well as the online cultural divides and imagine what constitutes harm. In its broadest sense that includes the oppressive practice, shame, embarrassment, and bias that researchers-and practitioners, ministries, donors, and developers-may cause by their interventions (Traxler 2012). This is clearly a challenging issue for a body such as UNESCO, with its high-level inter-ministerial contacts and concerns about the sovereignty of member-state governments. It is, however, important for the credibility and authenticity of learning with such a pervasive and ubiquitous technology as the mobile phone.

\section{UNESCO's work in progress}

We, and many others, hope that UNESCO's publications, projects, and events on mobile learning have made, and continue to make, a valuable contribution to the field by raising awareness of the unique benefits of mobile learning - as well as its associated challengesand by shining a light on key research and initiatives from around the world. UNESCO will continue to publish papers related to mobile learning in its capacity as a clearinghouse. Because its four pilot projects for teacher development are currently underway, an evaluation report will be published in 2014.

In practical terms, mobile learning at UNESCO is a work in progress, building on the growing body of empirical evidence that points to the educational benefits of mobile learning, but simultaneously trying out new approaches to education delivery and support. Given that the success or failure of any ICT in education effort is closely tied to the local context in which it is implemented - even more so with mobile learning-it is clear that mistakes will be made as projects are rolled out for the first time in communities. As illustrated above, several significant challenges remain.

Mobile learning has the potential to help improve the quality of teaching, learning, and education management. This potential is especially appealing at a time when poor-quality teaching and a lack of educational resources characterise many low-performing education 
systems. The number of people using mobile devices continues to rise, and increased interest in mobile learning is resulting in more mobile learning initiatives.

UNESCO acknowledges that "mobile technology is not and never will be an educational panacea" (West and Vosloo 2013, p. 21). However, "it is a powerful and often overlooked tool-in a repertoire of other tools - that can support education in ways not possible before" (p. 21).

In the future, UNESCO will explore possible themes for forthcoming Mobile Learning Week events, as will other organisations convening their own mobile learning conferences. Perhaps in this Introduction we have provided some ideas.

\section{References}

Beddall-Hill, N., \& Raper, J. (2010). Mobile devices as 'boundary objects' on field trips. Journal of the Research Center for Educational Technology, 6(1), 28-46.

Botha, A., Batchelor, J., de Waard, I., \& Traxler, J. (2012). Towards a mobile learning curriculum framework. In P. Cunningham \& M. Cunningham (Eds.), IST-Africa 2012 Conference proceedings. Dublin: International Information Management Corporation.

Coleman, H. (Ed.) (2011). Dreams and realities: Developing countries and the English Language. London: British Council.

Colls, T. (2009). The death of language? BBC Radio News, 19 October. http://news.bbc.co.uk/today/hi/ today/newsid_8311000/8311069.stm.

Creanor, L., Gowan, D., Howells, C., \& Trinder, K. (2006). The learner's voice: A focus on the e-learner experience. In Proceedings of the Fifth International Conference on Networked Learning, Lancaster University, Lancaster, United Kingdom. http://www.networkedlearningconference.org.uk/past/ nlc2006/abstracts/creanor.htm.

Creanor, L., Trinder, K., Gowan, D., \& Howells, C. (2006). Who's learning and how? Researching the learner experience. In Proceedings of the 23rd Annual ASCILITE Conference: Who's learning? Whose technology? Sydney Australia, 3-6 December (pp. 179-188).

Dodson, L., Sterling, R., \& Bennett, J. (2013). Minding the gaps: Cultural, technical and gender-based barriers to mobile use in oral-language Berber communities in Morocco. In Proceedings of ICTD, the Sixth International Conference on Information and Communications Technologies and Development (pp. 79-88). Cape Town: ACM.

Dykes, G., \& Knight, H. R. (2012). Mobile learning for teachers in Europe: Exploring the potential of mobile technologies to support teachers and improve practice. Paris: UNESCO.

Fritschi, J., \& Wolf, M. A. (2012a). Mobile learning for teachers in North America: Exploring the potential of mobile technologies to support teachers and improve practice. Paris: UNESCO.

Fritschi, J., \& Wolf, M. A. (2012b). Turning on mobile learning in North America: Illustrative initiatives and policy implications. Paris: UNESCO.

Goggin, G. (2006). Cell phone culture. Abingdon: Routledge.

GSMA [Groupe Speciale Mobile Association] (2012). GSMA announces new global research that highlights significant growth opportunity for the mobile industry. Press release, October 18. http://www.gsma. $\mathrm{com} /$ newsroom/gsma-announces-new-global-research-that-highlights-significant-growth-opportunityfor-the-mobile-industry.

Hylén, J. (2012). Turning on mobile learning in Europe: Illustrative initiatives and policy implications. Paris: UNESCO.

Isaacs, S. (2012a). Mobile learning for teachers in Africa and the Middle East: Exploring the potential of mobile technologies to support teachers and improve practice. Paris: UNESCO.

Isaacs, S. (2012b). Turning on mobile learning in Africa and the Middle East: Illustrative initiatives and policy implications. Paris: UNESCO.

ITU [International Telecommunications Union] (2013). The world in 2013: ICT facts and figures. http:// www.itu.int/en/ITU-D/Statistics/Pages/facts/default.aspx.

Jara, I., Claro, M., \& Martinic, R. (2012). Mobile learning for teachers in Latin America: Exploring the potential of mobile technologies to support teachers and improve practice. Paris: UNESCO.

Lugo, M. T., \& Schurmann, S. (2012). Turning on mobile learning in Latin America: Illustrative initiatives and policy implications. Paris: UNESCO. 
News24 (2013). Mxlish the 12th official SA language. Cape Town: News24. http://www.news24.com/ Technology/News/Mxlish-the-12th-official-SA-language-20130328.

Rindels, M. (2013). To save endangered languages, tribes turn to tech. Washington, DC: WTOP Radio. http://www.wtop.com/209/3288726/To-save-endangered-languages-tribes-turn-to-tech.

Rosenberg, T. (2011). Ancient tongue meet digital age. New York Times, 9 December, p. 15. http://www. nytimes.com/2011/12/11/magazine/everyone-speaks-text-message.html?pagewanted=all.

Shortis, T. (2007). Revoicing TXT: Spelling, vernacular orthography, and "unregimented writing". In S. Posteguillo, M. J. Esteve, \& M. L. Gea-Valor (Eds.), The texture of Internet: Netlinguistics in progress (pp. 2-23). Newcastle: Cambridge Scholars Publishing.

Shuler, C., Winters, N., \& West, M. (2012). The future of mobile learning: Implications for policy makers and planners. Paris: UNESCO.

So, H. J. (2012). Turning on mobile learning in Asia: Illustrative initiatives and policy implications. Paris: UNESCO.

Tembe, J., \& Norton, B. (2011). English education, local languages and community perspectives in Uganda. In H. Coleman (Ed.), Dreams and realities: Developing countries and the English language (pp. 117-140). London: British Council.

Thurlow, C. (2003). Generation Txt? The sociolinguistics of young people's text-messaging. Discourse Analysis Online, 1(1). http://extra.shu.ac.uk/daol/articles/v1/n1/a3/thurlow2002003-paper.html.

Traxler, J. (2010). Sustaining mobile learning and its institutions. International Journal of Mobile and Blended Learning, 2(4), 58-65.

Traxler, J. (2011). Mobile learning: Starting in the right place, going in the right direction? International Journal of Mobile and Blended Learning, 3(1), 57-67.

Traxler, J. (2012). Ethics and ICTD research. In A. Chib \& R. Harris (Eds.), Linking research to practice in Asia: ICT for development research, management and perspectives (pp. 68-81). Ottawa: International Development Research Centre.

Traxler, J., \& Kukulska-Hulme, A. (2006). The evaluation of next generation learning technologies: The case of mobile learning. Paper presented at the 13th meeting of the Association for Learning Technology, 5-7 Sept 2006, Heriot-Watt University, Scotland. In ALT-C2006: The next generation. Research proceedings of ALT-C2006. Oxford: Association for Learning Technology.

UIS [UNESCO Institute of Statistics] (2013). A teacher for every child: Projecting global teacher needs from 2015 to 2030. UIS fact sheet, no. 27, October 2013. http://www.uis.unesco.org/Education/ Documents/fs27-2013-teachers-projections.pdf.

UNESCO (2005). Mobile learning for expanding educational opportunities. Workshop report, International Workshop on Mobile Learning for Expanding Educational Opportunities, Tokyo, 16-20 May. http:// www2.unescobkk.org/elib/publications/074/m-learning.pdf.

UNESCO (2009). Five functions for UNESCO. http://www.unesco.ru/en/?module=pages\&action=view\&id= 19.

UNESCO (2010). UNESCO and Nokia sign partnership to use mobile technologies to further goals of Education For All. Press release, October 19. http://www.unesco.org/new/en/media-services/single-view/news/ unesco_and_nokia_sign_partnership_to_use_mobile_technologies_to_further_goals_of_education_for_ all/.

Vosloo, S. E. (2012). Mobile learning and policies: Key issues to consider. Paris: UNESCO.

West, M. (2012). Mobile learning for teachers: Global themes. Paris: UNESCO.

West, M., \& Vosloo, S. E. (2013). UNESCO policy guidelines for mobile learning. Paris: UNESCO.

Worldreader (2011). Starting an E*Reader program at Ntimigom School with the Kilgoris Project. San Francisco: Worldreader. http://www.worldreader.org/uploads/Worldreader\%20Kilgoris\%20Report\% 20Oct-2011.pdf.

John Traxler (United Kingdom) is the world's first Professor of Mobile Learning, and, since September 2009, a full Professor and director of the Learning Lab at the University of Wolverhampton. He is a founding director and current vice president of the International Association for Mobile Learning, an executive committee member of the USAID mEducation Alliance, and associate editor of the International Journal of Mobile and Blended Learning and of Interactive Learning Environments. He has co-written a guide to mobile learning in developing countries for the Commonwealth of Learning and is co-editor, with Agnes Kukulska-Hulme, of the definitive book, Mobile Learning: A Handbook for Educators and Trainers. They are now working on a second book, Mobile Learning: The Next Generation, to be published in 2014. He is co-authoring Key Issues in Mobile Learning: Research and Practice, with Norbert Pachler and John Cook, and Mobilizing Mathematics: Case Studies of Mobile Learning, with Helen Crompton. 
Steve Vosloo (South Africa) is a programme manager at Mobiles for Development (M4D), with a particular focus on mobile learning, youth, and ICTs. Up until the end of 2013, he was leading the mobile learning team at UNESCO; he managed several global projects and represented UNESCO on the executive committee of the mEducation Alliance. Previously he was the fellow for 21st Century Learning at the Shuttleworth Foundation. He founded the m4lit (mobiles for literacy) project, which demonstrated the enormous potential of mobile publishing to support teen reading and writing in South Africa and Kenya. In 2007 he was a research fellow at Stanford University, studying youth and digital media. He has presented at many international conferences on M4D, mlearning, and ICT4D, and has written a number of research papers on these topics. He is currently Head of Mobile at Pearson South Africa. He holds a master's degree in Information Systems from the University of Cape Town. 